\title{
KEPEMIMPINAN TRANSFORMATIF K. H. AHMAD DAHLAN DI MUHAMMADIYAH
}

\author{
Oleh: \\ Ruslan Rasid(ruslanrasyid61@gmail.com) \\ Program Pascasarjana Sekolah Tinggi Agama Islam Negeri (STAIN) Sorong
}

\begin{abstract}
ABSTRAK
K. H. Ahmad Dahlan sebagai pelopor sekaligus pendiri persyarikatan Muhammadiyah yangbercirikan gerakan Islam, gerakan dakwah,gerakan purifikasi, dan pembaharuan. Secara historis, faktor-faktor yang melatar belakangi berdirinya Muhammadiyahkarena adanya pemahaman agama Islamyang beragam di pulau Jawa, kondisi keadaan masyarakat Kauman-Yogyakarta ketikaitu yang jauh dari kesejahteraan, pelayanan kesehatan dan pendidikan bagi pribumi. Hal tersebut mendorong K. H. Ahmad Dahlan untuk melakukan upaya perubahan, mengembalikan kemurnian ajaran Islam, mengangkat harkat, dan harga diri masyarakat Kauman sehingga dengan gaya seperti itu terbentuk pola-pola kepemimpinan transformatif. Kajian ini menggunakan pendekatan kualitatifjenis penelitian historis. Metode ini dianggap paling relevan dalam menelusuri pola, strategi dan gaya kepemimpinan transformatif K. H. Ahmad Dahlan diMuhammadiyah. Hasil kajian menunjukkan bahwa K. H. Ahmad Dahlan memiliki jiwa kepemimpinan transformatif yang bersifat karismatik, motivator, dan memiliki kecerdasan intektual serta berpikir visioner. Selain itu pula, K. H. Ahmad Dahlan memiliki kemampuan untuk melihat dan memahami secara emosional seluruh fenomena yang terjadi.Bahkan K. H. Ahmad Dahlan turut berempati tinggi terhadap posisi dan keadaan orang lain, terutama dalam hal perbedaan pandangan atau pendapat.Pandangannya tersebut bersifat inklusif relativis yaitu memandang positif terhadap perbedaan yang ada dan menganggap bahwa itu bukanlah perbedaan yang hakiki/mutlak namun disebabkan karena adanya perbedaan faktor-faktor luar. K.H. Ahmad Dahlan merupakan seorang pemimpintranformatif yang senantiasa bergerak maju dan berinovasi sekaligus seorang tokoh pembaharu Islam di Indonesia.
\end{abstract}

Kata Kunci: Kepemimpinan Transformatif, K. H. Ahmad Dahlan, Muhammadiyah.

\begin{abstract}
K.H. Ahmad Dahlan as the pioneer founder persyarikatan Muhammadiyah Islamic movement, characterized by the movement of da'wah, purification, and renewal. Historically, the factors underlying the establishment of Muhammadiyah were the understanding of diverse Islamic religions on the island of Java, the condition of the State society Kauman Yogyakarta-when it's away from welfare, health services and education for indigenous peoples. It encourages the K. H. Ahmad Dahlan to attempt change, restoring the purity of the teachings of Islam, elevating the dignity, and self-esteem of the community so that a style as Kauman village that formed the transformative leadership patterns. This study used a qualitative approach to the kind of historical research. This method is considered most relevant in tracing the pattern, strategy and leadership style of
\end{abstract}


transformative K. H. Ahmad Dahlan in Muhammadiyah. Results of the study show that K. H. Ahmad Dahlan has transformative leadership is charismatic, motivational speaker, and has intektual intelligence and visionary thinking. In addition, K. H. Ahmad Dahlan has the ability to see and understand emotionally the whole phenomenon occurred. Even $\mathrm{k} . \mathrm{h}$. Ahmad Dahlan participated and empathize to position and circumstances of others, especially in terms of the difference in views or opinions. His view is relativis inclusive i.e. looked positively towards differences and assume that it is not an essential difference/absolute but caused due to the difference of external factors. K.h. Ahmad Dahlan was a leader of the tranformatif that is always moving forward and innovating while a reformer of Islam in Indonesia.

\section{PENDAHULUAN}

Kepemimpinan dari seorang pemimpin yangtransformatif tidak terlepas dari gaya kepemimpinannya dalam menggerakkan seluruh elemen pada sebuah organisasi dengan tujuan agar dinamika di dalam berorganisasi senantiasa terjaga,oleh karena itu setidaknya seorang pemimpin memiliki 4 komponen yang melekat padanya yang saling berkaitan satu sama lainnya yaitu: Idealized Influence Charisma, Inspirational Motivation, Intellectual Stimullation, Individual Consideration(Suminto, 2016). Jika hal ini mampu diaktualisasikan oleh seorang pemimpin/leader maka masa depan suatu organisasi akan senantiasa eksis.Selain itu pula kepemimpinan transformasional yakni model kepemimpinan yang secara terus menerus melakukan perubahan untuk peningkatan organisasi(Afandi, 2013).dengan kata lain senantiasa bergerak maju serta mengikuti perkembangan zaman baik dalam hal pengembangan secara struktural maupun pengembangan visi dan misi sehingga organisasi itu menjadi hidup.

Muhammadiyahmerupakan organisasi Islam yang lahir di Yogyakarta pada tanggal 18 Nopember 1912 dengan K. H. Ahmad Dahlan sebagai pelopor sekaligus pendirinya(Anurkarina, 2015) berciri khaskan gerakan Islam, gerakan dakwah, dan gerakan tajdid/pembaharuan (Ali, 2016). Secara historis faktor yang menjadi latar belakang berdirinya Muhammadiyahadalah adanyapemahaman agama umat Islam di Indonesia yang beragamdan kondisi keadaan masyarakat Kauman-Yogyakarta ketika itu yang jauh dari kesejahteraan dan pendidikan. Oleh karena itu K. H. Ahmad Dahlan mempunyai gagasan utuk membuat sebuah lembaga pendidikan serta mengembangkan Muhammadiyah sebagai media yang bertujuan membebaskan bangsa dari 
permasalahan-permasalahan di atas. Salah satu upaya yang dilakukan oleh K. H. Ahmad Dahlan diawal berdirinya persyarikatan Muhammadiyahyang terkenal sebagai gerakan spirit Q.S. AlMa'un(Huda, 2011) yang inti dari gerakan tersebut yaknikepedulian sosial dengan jalan menyantuni anak yatim, kaum mustad'afin dan janda di Yogyakarta ketika itu.Adapun dalam bidang pendidikan yaitu dilakukan dengan mendirikan sekolah Muhammadiyah tingkat dasar, madrasah mu'allimin/sekolah khusus calon guru (kweekschoolMuhammadiyah) yang pembelajarannya memadukan antara ilmu agama dan ilmu pengetahuan, serta bidang kesehatandengan membangun rumah sakit Muhammadiyah(Pribadi, 2010). Upayaupaya yang dilakukan oleh K. H.Ahmad Dahlan ini mampu membawa perubahan yang begitu signifikan pada masa itu. Hal itu dikarenakan pemikirannya yang bersifatvisioner-antisipatoris(Ali, 2016); itulah yang membuat Muhammadiyah maju dan eksis hingga saat ini.Tulisan ini bertujuan mengkaji pola pemikiran, pendekatan serta strategi kepemimpinan transformatif K. H. Ahmad Dahlan (18681923) di Muhammadiyahdengan cara menggali dari beberapa jurnal-jurnal yang terdahalu yang berkaitan dengan $\mathrm{K}$.
H.Ahmad Dahlan di Muhammadiyah sehingga memperkaya khazanah keilmuan mengenai pemikiran, perjuangannya ketika itu danterutama mengenai permasalahan kepemimpinan transformatifnya di Muhammadiyah.

Kajian ini memfokuskan pada pertanyaanpertanyaan yang berkaitan sebagai berikut: Bagaimana konsep pemikiran dan pendekatan dakwah yang dilakukan olehK. H.Ahmad Dahlan di Muhammadiyah ketika itu? Bagaimana strategi kepemimpinan transformatif K. H. Ahmad Dahlan di Muhammadiyah?

Terdapat beberapa karya tulis baikberupa jurnal hasil penelitian, tesis, skripsi, buku yang mengangkat atau membahas tentang K. H. Ahmad Dahlan seperti yang dilakukan oleh: Maman Abdul Majid Binfas (2014) membahas tentang Tapak Perbezaan Asal Usul Gerakan Muhammadiyah dan NU di Indonesia, Mohamad Ali (2016) membahas tentang Pendidikan Berkemajuan: Refleksi Praksis Pendidikan KH, Ahmad Dahlan, Fandi Ahmad (2015) membahas tentang Pemikiran K. H. Ahmad Dahlan Tentang Pendidikan, Fenty Windy Anurkarina (2011) membahas Perilaku Tokoh K. H. Ahmad Dahlan dalam Novel Sang Pencerah Karya Akmal Nasery Basral, 
Mohamad Ali (2016)Membedah Tujuan Pendidikan Muhammadiyah,Najib Burhani (2017) membahas tentang Pascawacana Mitsuo Nakamura dan Studi Tentang Muhammadiyah, Ahmad Faizin Karimi (2012) membahas tentang Pemikiran dan Perilaku Politik K. H. Ahmad Dahlan, Nanang Sugiono (2016) yang membahas tentang Nilai-Nilai Pendidikan Karakter dalam buku Kebiasaan-Kebiasaan Inspiratif K. H. Ahmad Dahlan.

Pada penelitian-penelitian tersebut secara spesifik belum ada yang berfokus membahas mengenai pola pemikiran,serta strategi kepemimpinan transformatif K. H. Ahmad Dahlan di Muhammadiyah; oleh karenanya, penelitian ini dilakukan untuk mengelaborasibagaimana pola yang dilakukan K. H. Ahmad Dahlan dalam kepemimpinannya di Muhammadiyah ketika itu. sehingga dapat diketahui pola gaya kepemimpinan transformatif K. $\mathrm{H}$. Ahmad Dahlan baik pra maupun pasca berdirinya Muhammadiyah di KaumanYogyakarta.

\section{METODE PENELITIAN}

Kajian ini menggunakan metode pendekatan secara kualitatif, adapun jenis kualitatif yang digunakanyaitu jenis historis,sebuah proses pengumpulan data yang telah terjadi di masa lalu.Hal ini dipandang cocok untuk melihat kepemimpinan transformatif K. H. Ahmad Dahlan di Muhammadiyah masa lalu. Prof. Dr. Kuntowijoyomenyimpulkan penelitian yang menggunakan metodologi sejarah harus didasarkan empat tahap yaitu, pertama,heuristik, yakni pengumpulan data sejarah harus benar-benar valid dan otentik sebagai data primer dan sekunder. Kedua, pengujian kebenaran data yang disajikan. Ketiga, interpretasi, fakta data yang tadi diinterpretasikan dengan ilmu sosial atau ilmu bantuan lainnya sehingga memahami hakikat di balik sejarah atau fakta sejarah. keempat: menyimpulkan dengan menuliskannya. Tahapan ini disebut dengan historiografi sehingga tidak asal menarik sebuah kesimpulan(Sjamsudin, 2012).

\section{HASIL DAN PEMBAHASAN}

Mengenal Sosok K. H. Ahmad Dahlan Sang Pembaharu/Al-Mujaddiddari

\section{Kauman.}

K. H. Ahmad Dahlan dilahirkan di Yogyakarta 01 Agustus 1873dengan nama kecil yaitu Muhammad Darwis merupakan anak dari K. H. Abu Bakar bin Sulaiman merupakan salah seorang ulama dan khatib di Masjid Besar Kasultanan Yogyakartadi zamannya dan seorang ibu yang merupakan anak dari H. Ibrahim yang menjabat sebagai Penghulu Kesultanan 
Yogyakarta Hadiningrat. K. H. Ahmad Dahlanterlahir dari keluargayang dihormati dan disegani di Kauman-Yogyakarta serta hidupnya dikeliling para ulama;oleh karenanya,semenjak kecil beliau telah mendapatkan pembinaan ilmu agama langsung dari ayahnya. K. H. Ahmad Dahlan juga dapat dikatakan tidak pernah memasuki pendidikan formal, pengetahuan yang dimilikinya didapatkan secara autodidak(Wadi, 2012) dan (Dahlan, 2014).

Ketika berumur 15 tahun pada tahun 1888, ia melakukan perjalanan ibadah haji yang pertama dan bermukim selama 5 tahun di Makkah Al Mukarramah dalam rangka berguru dan memperdalam ilmu agamanya bersama para masyayikh. Kemudian pada tahun 1902 kembali lagi menunaikan ibadah haji dan bermukim selama 3 tahun lagi. Hal ini merupakan perintah Sultan Hamengkubuwono VII dalam rangka melakukan diskusi-diskusi perihal pergerakan pembaharuan Islam di Timur Tengah dan mempelajari perkembangan Islamdikarenakan ketika itu banyak lahir tokoh pemikir pembaharu Islam yang bangkit dari keterpurukannya pasca runtuhnya dinasti Turky Utsmany hingga penjajahan Barat ketika itu (Sukriyanto AR).Sepulangnya dari ibadah haji yang kedua pada tahun 1905 K. H. Ahmad
Dahlan mengajarkan apa yang didapatinya selama di sana danpemikiran-pemikiran tersebut menjadi sebuah inspirasi dan kerangka pergerakan perjuangannya dalam upaya pendirian persyarikatan Muhammadiyahdi Yogyakarta.

Kepemimpinan Transformatif $\mathbf{K}$. $\mathbf{H}$. Ahmad Dahlan dalam Merekonstruksi Arah Kiblat Masjid Agung Yogyakarta

Dilatarbelakangi banyaknya masjidmasjid di Pulau Jawa hingga Masjid Agung Yogyakarta yang kiblatnya menghadap barat pas yakni menghadap ke Ethopia/Afrika, tidak tepat ke arah barat laut 24 derajat (arah kiblat). Setelah adanya pencocokan dengan ilmu falak yang telah dipelajarinya terdahulu serta dibantu menggunakan kompas dan peta dunia, didapati banyak yang tidak menghadap kiblat.K. H. Ahmad Dahlan berpandangan bahwa menghadap kiblat merupakan syarat sahnya shalat. K. H. Ahmad Dahlan juga berpandangan bahwa, umat Islam yang tidak bisa melihat Ka’bah secara langsung waktu melakukan shalat, cukup menghadapkan wajahnya ke arah Ka’bah. Pandangan K. H. Ahmad Dahlan sejalan dengan catatan Kyai Syuja’, dengan istilah jihatu al-Ka'bah, dipergunakan oleh K. H. Ahmad Dahlan untuk menunjukkan bahwa umat Islam yang berada di luar Makkah dianggap sah bila shalat menghadap ke 
arah Ka’bah dan bukan 'ain alKa'bah(Sakirman, 2012). Oleh karenanya, selama kurang lebih setahun melakukan dialog-diaolog mengenai rekonstruksi arah kiblat ini hingga pada akhirnya $\mathrm{K}$. H.Ahmad Dahlan mengumpulkan para ulama untuk membahas permasalahan kiblat ini di Yogyakarta. Walaupun hasil musyawarah tersebut tidak menghasilkan sebuah keputusan secara mufakat dikarenakan adanya pro dan kontra mengenai rekonstruksi arah kiblat tersebut, namun sikap Idealized Influence Charisma dan Intellectual Stimullation(Suminto, 2016), perpaduan antara ide dan fakta (Wekke \& Sari, 2013) yang dimiliki oleh K. H. Ahmad Dahlan mampu menggugah dan menarik hatipemuda-pemuda yang senantiasa menguping pembahasan arah kiblat tersebut yang juga merupakan kerabat kepala penghulu keraton(Sakirman, 2012). Terjadilah insiden perubahan garis shaf pada masjid agung Yogyakarta ketika itu atas dasar inisiatif mereka sendiri tanpa adanya perintah dan keterkaitannya K. H. Ahmad Dahlan.K. H. Ahmad Dahlan sebagai pribadi yang memiliki jiwa kepemimpinan transformatif dan berfikir secara inklusif relativis (Mulkhan:2010) dalam artian memahami bahwa dibutuhkannya jiwa sportif dan universal yang mungkin bernilai positif pada orang lain, sehinggaK. H. Ahmad Dahlan menerapkan arah kiblat dengan cara membuat garis shaf pada Langgar Kidul yang dibuatnya sendiri.

\section{Strategi dan PemikiranK. H. Ahmad Dahlan Mendirikan Persyarikatan Muhammadiyah di Kauman- Yogyakarta}

Menurut A.R. Fakhruddin: secara normatif-konseptual, identitas atau ciri khas Muhammadiyah dialamatkan pada gerakan Islam, gerakan dakwah dan gerakan tajdid/pembaharuan(Ali, 2016). maka jauh sebelum pendirian Muhammadiyah pada tahun 1912 yang dilakukan oleh K. H. Ahmad Dahlan, telah banyak gerakan atau upaya yang mewarnai perjuangannya diantaranya: pertama, setelah pulangnya K. H. Ahmad Dahlan menunaikan ibadah haji, menjalin kedekatan dengan pemerintahan kolonial Hindia Belanda dengan jalan menjadi seorang pendidik di KweekschoolGubernamen Jetis milik kolonial Belanda. Hal ini dapat dikatakan terlihat unik dikarenakan K. H. Ahmad Dahlan terhadap Hindia Belanda bercorak Rival-Moderat(Febriyanto, 2017) dalam artian mengakui keberadaan kolonial Hindia Belanda sebagai pemerintah ketika itu sehingga tidak ditemukan tulisantulisan yang mengarah untuk melakukan 
pertentangan terhadap penjajahan kolonial Belanda, namun bukan berarti K. H. Ahmad Dahlan memihak kepada Belanda karena perjuangan dan pola pemikiran $\mathrm{K}$.

H. Ahmad Dahlan memperhatikan kaum yang lemah dan penindasan yang terjadi ketika itu.Kedua, bergabungnya K. H. Ahmad Dahlan dengan organisasi Budi Utomo(Syukri \& Ismail, 2014) dengan salah satu tujuannya ialah memasukkan nilai agama ke dalam organisasi tersebut sesuai kebutuhan para anggota organisasi Budi Utomosehingga melalui organisasi tersebut K. H. Ahmad Dahlan mendapatkan dorongan agar membuat sekolah Islam.Ketiga, bergabung dengan Jam'iatul Khair dan Syarikat Islam. Keempat, melakukan tabligh dan lawatan ke berbagai daerah di pulau Jawa dalam rangka menyuarakan umat Islam harus kembali kepada Al-Qur'an dan As-Sunnah serta menghindari dari segala bentuk amalan yang menjerumuskan pelakunya dalam kesyirikan,khurafa'at, dan tahayul.Kesemuanya itu merupakan strategi dan pola kepemimpinan transformatif yang dilakukan oleh K. H. Ahmad Dahlandalam menyiapkan wadah pergerakannya.

Pada tanggal 18 Nopember 1912 lahirlah persyarikatanMuhammadiyah dibawah kepemimpinan K. H. Ahmad Dahlan langsung. Adapun terobosan yang dilakukan K. H. Ahmad Dahlan setelah terbentuknya Persyarikatan Muhammadiyah ini di antaranya, pertama: K. H. Ahmad Dahlan mengajukan surat permintaan badan hukum kepada Gubernur Jenderal Hindia Belanda dengan mengirim Statuten Muhammadiyah.Permintaan izin tersebut baru disahkan oleh Gubernur Jenderal Hindia Belanda pada 22 Agustus 1914 melalui Besluit Gubernur Jenderal No. 81(Febriyanto, 2017).Ijin operasi yang dikeluarkan oleh kolonial ini baru hanya sebatas wilayah Yogyakarta saja.Kedua:dikarenakan waktu itu masih fase pengenalan pembaharuan Muhammadiyah, K. H. Ahmad Dahlan banyak melakukan silaturahmi, munaqasyah/diskusi ilmiah, taushiyah, serta memberikan keteladanan dalam praktek pengamalan agama Islam.ketiga: terbentuknya perangkat awal dalam tubuh Muhammadiyah seperti, pembentukan majelis tabligh, majelis sekolahan dan pengajaran yang (sekarang menjadi majelis pendidikan dasar dan menengah), majelis taman pustaka, dan majelis penolong kesengsaraan umum,'aisyiyah, gerakan kepanduan HisbulWathan, menerbitkan majalah SuaraMuhammadiyah, selain itu pula mendirikan panti asuhan yatim/piatu.Apabila kita lihat dengan 
seksama strategi kepemimpinan transformatif K. H. Ahmad Dahlan diMuhammadiyah ketika itu sistematis dan berkemajuan dari waktu ke waktu sebab seorang pemimpin yang transformatif setidaknya memiliki pedoman di antaranya: menyatakan visi yang jelas dan menarik, menjelaskan bagaimana visi tersebut dapat dicapai, bertindak secara rahasia dan optimistis, menggunakan tindakan dramatis dan simbolis untuk menekankan nilai nilai penting, memimpin dengan memberikan contoh, memberikan kewenangan kepada orang-orang untuk mencapai visi yang telah dibuat (Suminto, 2016). Hal tersebut telah dilakukan oleh K. H. Ahmad Dahlan pada masa kepemimpinannya di Muhammadiyah 1912-1923.Selain itu pula, terdapat tiga poin upaya yang dilakukan oleh K. H. Ahmad dalam penerapannya kepada murid dan warganya di Muhammadiyahyaitu: pengetahuan sejati tentangmenyeimbangkan elemen kehidupan dapat dicapai melalui sikap kritis dan pikiran terbuka dengan menggunakanakal sehat dan fokus pada kebenaran dengan hati yang murni, akal sehat sebagai dasarkebutuhan hidup manusia, 'ilmu mantiq' atau logika merupakan salah satu mata pelajaran penting dalampendidikan untuk akal manusia untuk melakukan pemikiran rasional(Miftachul Huda \& Kartanegara, 2015). Sehingga mencapai esensi kepemimpinan transformatif/sharing of power(Suminto, 2016) dengan melibatkan seluruh elemen secara bersama-sama.

\section{KESIMPULAN}

Kepemimpinan transformatif K. H. Ahmad Dahlan selain berperan sebagai seorang mujaddid/pembaharu di zamannya mampu membawa perubahan terhadap pergerakan Islamdi Pulau Jawa pada umumnya.Model kepemimpinannya yang karismatik, inspiratif, pemberi teladan/panutan serta memiliki kecerdasan intelektual dan berfikir secara visioner-antisipatoris mampu menjadikan Muhammadiyah sebagai gerakan Islam yang berkemajuan dan menjadi cikal bakal perjuang kemerdekaan Republik Indonesia. Sehingga pada tahun 1961 Presiden Soekarno memberikan gelar Pahlawan Nasional kepada K. H. Ahmad Dahlan dikarenakan beberapa faktor salah satunya sebagai pelopor kebangkitan ummat Islam yang sadar akan nasibnya sebagai bangsa yang dijajahdan masih harus belajar dan berbuat.

Perjuangan K. H. Ahmad Dahlan dalam hal kepemimpinan di Muhammadiyah menjadi sebuah gambaran yang jelas 
bahwa seorang pemimpin itu harus memiliki perilaku visioning, yaitu memberikan rumusan masa depan; inspiring, yaitu senantiasa memotivasi diri dan bawahan; stimulating, yaitu berfikir maju dengan melahirkan ide-ide yang baru; coaching, yaitu melatih satu demi satu hingga sesuai dengan apa yang kita harapkan; dan team building, yaitu bekerja secara team/bersama-sama/saling bahumembahu. Oleh karena itu, masalah yang lebih penting bagi seorang pemimpin transformasional selalu mempunyai visi yang kuat, selalu berusaha ingin mengembangkan organisasi yang dipimpinnya, dengan demikian esensi kepemimpinan transformasionalnya mampumenghasilkanperubahan

secarabersama-sama dalam artian mengalami perubahan ke arah yang lebih luas, lebih tinggi, dan lebih mendalam, serta lebih baik.

\section{DAFTAR PUSTAKA}

Ali, M. 2016. "Membedah Tujuan Pendidikan Muhammadiyah". Profetika, Jurnal Studi Islam, 17(1), 43-56.

Anurkarina, F. W. 2015. "Perilaku Tokoh K. H. Ahmad Dahlan dalam Novel Sang Pencerah Karya Akmal Nasery Basral."Kembara: Jurnal Keilmuan Bahasa, Sastra Dan Pengajarannya, I(April), 34-42.

Dahlan, M. 2014. K.H. Ahmad Dahlan sebagai Tokoh Pembaharu, XIV, 122131.

Huda, S. UIN S. A. S. 2011. Teologi Mustad'afin di Indonesia: Kajian atas TeologiMuhammadiyah.TSAQAFAH: Jurnal Peradaban Islam, 7(2), 345374.

https://doi.org/10.21111/tsaqafah.v7i2 .8 .

Karimi, Ahmad Faizin.2012. Pemikiran dan Perilaku Politik K. H. Ahmad Dahlan. Gresik: Penerbit:Muhipress.

Mulkhan, Abdul Munir. 2010.Kiai Ahmad Dahlan: Jejak Pembaharuan Sosial dan Kemanusian-Kado Satu Abad Muhammadiyah. Jakarta: Penerbit: Kompas.

Pribadi, S. A. T. 2010. "Kiprah K. H. Ahmad Dahlan dalam Modernisasi Pendidikan Islam di Indonesia".Skripsi. Jakarta: Universitas Islam Negeri Syarif Hidayatullah.

Sakirman. 2012. "K. H. Ahmad Dahlan dan Gerakan Pelurusan Arah Kiblat di Indonesia". AKADEMIKA: Jurnal Pendidikan Islam, (http://ejournal.metrouniv.ac.id/index.php/aka demika/issue/view/22), 1-17.

Sjamsudin, H. 2012. Metodologi Sejarah. Yogyakarta: Ombak.

Suminto. 2016. Karakter Kepemimpinan Transformatif. Pedagogy: Jurnal Ilmiah Ilmu Pendidikan, 1-9.

Syukri, M., \& Ismail, M. 2018. Asal Usul Gerakan Pendidikan Muhammadiyah di Indonesia.Journal of Engineering Technology.VI (1), 258-270.

Wadi, H. 2012. Strategi Pengembangan dakwah K. H. Ahmad Dahlan di Yogyakarta dan TGH. Muhammad Zainuddin Abdul Majid di Lombok (Studi Komparasi) NASKAH. Tesis, 1, 1-32. 